\title{
market place
}

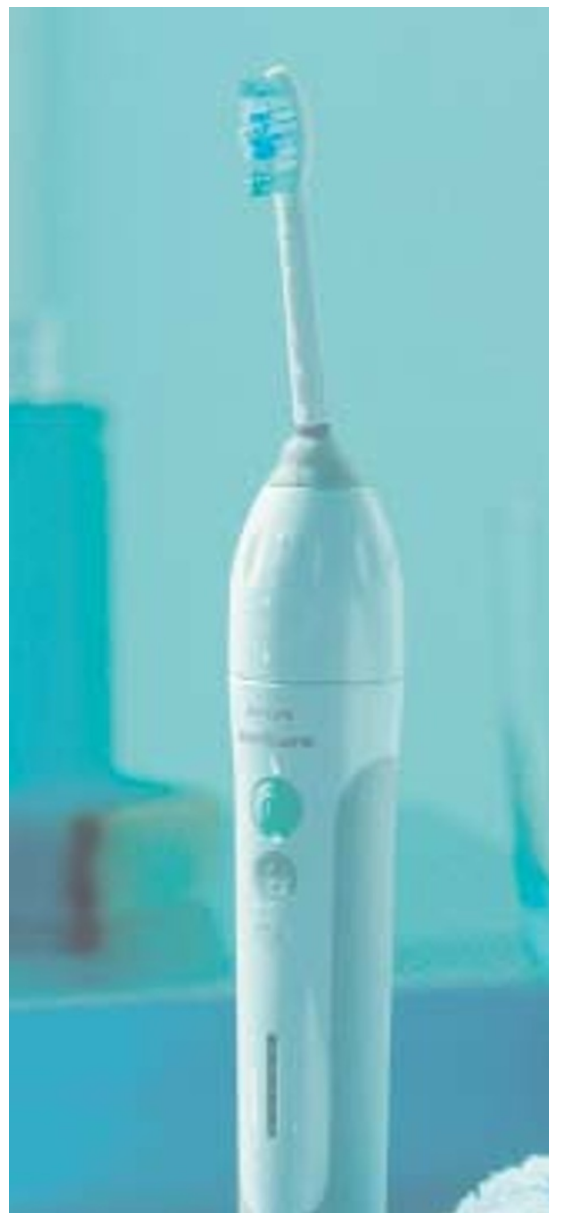

\section{The new Sonicare}

Philips Electronics is pleased to announce the launch of the

Sonicare Elite. Phillips claims

Sonicare Elite offers dental

professionals and their patients the most advanced power toothbrush to promote maximum oral health and hygiene.

The new Sonicare Elite with its patented second-generation sonic technology uses a combination of high frequency bristle tip motion and dynamic fluid cleaning action. The Sonicare Elite's new slim, angled neck and tapered brush head focuses powerful cleaning action in hard-to-reach interproximal, subgingival and posterior areas. Its dynamic cleaning power goes beyond the surface into deeper areas.

For more information phone 0800 0567222

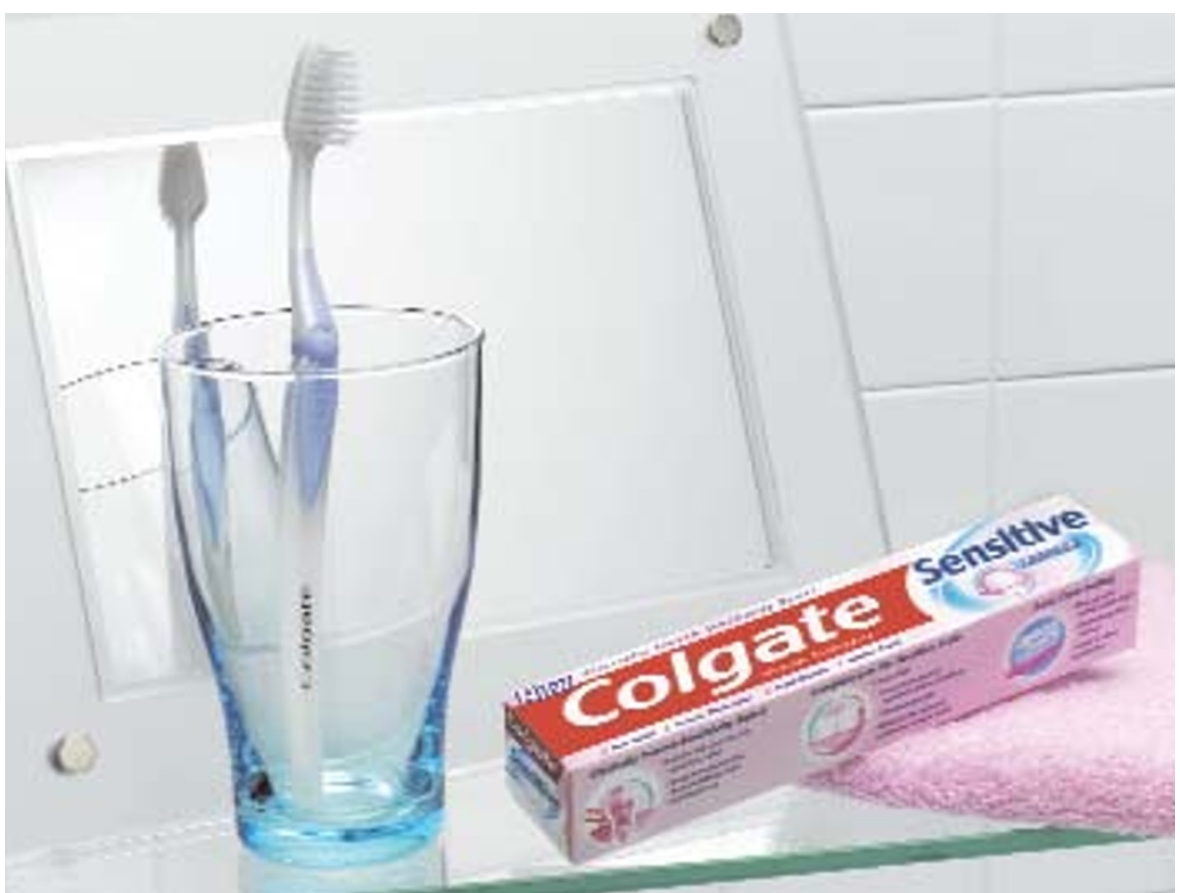

\section{Help your patients with sensitive}

Colgate is pleased to announce the launch of Colgate Sensitive toothpaste. The Colgate Sensitive toothpaste contains potassium citrate and fluoride which Colgate claims is clinically proven to provide immediate relief from pain and, when used daily, can provide long-term protection from dentine sensitivity.

Colgate found that 39 per cent of patients who suffer from sensitive teeth claim taste is the main reason for not regularly using toothpaste to tackle the problem. They say the minty blue and white striped formulation relieves sensitivity, freshens breath and contains an advanced whitening ingredient for an exceptional brushing experience. Colgate Sensitive will be available in $50 \mathrm{ml}, 75 \mathrm{ml}$, and in a $100 \mathrm{ml}$ pump.

To find out further information phone 01483401901.

\section{Four eyes are better than two}

Googles protective eye wear offers protection against cross contamination, according to Professional Dental Supplies. The range is lightweight and has been designed to fit over glasses and loops, and the frames are recyclable. Tinted amber lenses are available which eliminate glare from overhead lights.

Frames can be autoclaved up to 240 degrees Farenheit and the materials used do not contain latex. Phone 01480862081 for details. 